\title{
Increasing trends of Acinetobacter Baumannii infections in Emilia-Romagna, Italy
}

\author{
C Gagliotti ${ }^{1 *}$, A Pan ${ }^{1}$, R Buttazzi ${ }^{1}$, C Capatti ${ }^{2}$, E Carretto ${ }^{2}$, F Pedna ${ }^{3}$, M Sarti $^{4}$, C Venturelli ${ }^{5}$, ML Moro ${ }^{1}$ \\ From International Conference on Prevention \& Infection Control (ICPIC 2011) \\ Geneva, Switzerland. 29 June - 2 July 2011
}

\section{Introduction / objectives}

Estimation of occurrence of Acinetobacter baumannii isolates from the antimicrobial surveillance system of Emilia-Romagna, Italy, 2005-2009.

\section{Methods}

Data were collected through the laboratory based regional surveillance system. All isolates of $A$. baumannii isolates from blood, urine and respiratory samples were included in the analysis. Duplicates from the same patient/sample source within a 28 days period were excluded.

\section{Results}

Rates of A. baumannii bacteraemia significantly increased between 2005 and 2009, from 0.1 to 3.2 cases/100,000 inhabitants per year. The observed increase was due to carbapenem-resistant isolates, while the number of carbapenem-susceptible isolates remained substantially stable over the study period. Importantly, the occurrence of carbapenem-resistant isolates showed a steep five-fold increase between 2008 and 2009. These isolates belonged to an epidemic strain detected in several departments of 4 hospital trusts in the Region. Similar trends were observed for urine and respiratory isolates. The total number of isolates in blood, urine and respiratory specimens, including both colonizing and infecting strains, increased from 51 in 2005 to 826 in 2009, with rates rising from 1.5 to 19.0 isolates/100,000 inhabitants per year.

\section{Conclusion}

The temporal trends of $A$. baumannii infections are driven by carbapenem-resistant strains. A regional-wide outbreak of carbapenem-resistant A. baumannii

${ }^{1}$ Area Rischio Infettivo, Agenzia Sanitaria E Sociale Dell'Emilia-Romagna, Bologna, Italy

Full list of author information is available at the end of the article infections involving 4 hospital trust was observed in Emilia-Romagna in 2009.

\section{Disclosure of interest}

None declared.

\section{Author details}

${ }^{1}$ Area Rischio Infettivo, Agenzia Sanitaria E Sociale Dell'Emilia-Romagna, Bologna, Italy. ${ }^{2}$ Arcispedale S. Maria Nuova, Reggio Emilia, Italy. ${ }^{3}$ AUSL Ravenna, Ravenna, Italy. ${ }^{4}$ Nuovo Ospedale S. Agostino Estense, Italy.

${ }^{5}$ Policlinico di Modena, Modena, Italy.

Published: 29 June 2011

\section{doi:10.1186/1753-6561-5-S6-P292}

Cite this article as: Gagliotti et al.: Increasing trends of Acinetobacter Baumannii infections in Emilia-Romagna, Italy. BMC Proceedings 20115 (Suppl 6):P292.
Submit your next manuscript to BioMed Central and take full advantage of:

- Convenient online submission

- Thorough peer review

- No space constraints or color figure charges

- Immediate publication on acceptance

- Inclusion in PubMed, CAS, Scopus and Google Scholar

- Research which is freely available for redistribution

Submit your manuscript at www.biomedcentral.com/submit
() Biomed Central

\section{Ciomed Central}

